\title{
STUDY ON THE DEVELOPMENT AND GROWTH OF LARVES OF TIGER GROUPER Epinephelus fuscoguttatus (Forskal, 1775) AT DIFFERENT MEDIA TEMPERATURES
}

\author{
Virgia Wulandari*1, Indra G.Yudha² ${ }^{2}$ Eko Effendi ${ }^{2}$
}

\begin{abstract}
Water temperature has an influence on the development and growth of fish larvae. The appropriate water temperature can caused the development and growth of fish larvae optimum. This research aimed to study the effect of water temperature on the development and growth of brown marbled grouper larvae. This experimental design used a completely randomized design that had 3 treatments $\left(26-28^{\circ} \mathrm{C}, 28\right.$ $30^{\circ} \mathrm{C}, 30-32^{\circ} \mathrm{C}$ ) equipped with 3 replications each. The parameters observed were the duration of yolk absorption, morphogenesis of larvae, and growth of body length. Data of larval morphogenesis development were analyzed descriptively, while the duration of yolk absorption and larval growth were analyzed of variance and post hoc test using the Least Significant Difference (LSD). The results showed that water temperature influenced morphogenesis development, the duration of yolk absorption, and the growth of larval significantly different. The result showed, larvae had morphological development and duration of yolk absorption faster in warmer incubation media.
\end{abstract}

Keywords: Brown Marbled Grouper, Temperature, Duration of Yolk Absorption, Growth Length.

\section{Pendahuluan}

Usaha budidaya ikan kerapu macan (Epinephelus fuscoguttatus) mulai berkembang dari tahun 2005 dan sudah tercatat mendominasi permintaan pasar internasional (Nurdjana, 2006). Namun, produksi budidaya ikan kerapu masih terkendala dalam proses budidaya pada fase larva.

Salah satu faktor lingkungan yang berperan dalam fase larva yaitu suhu. Suhu memberikan pengaruh terhadap proses kecepatan reaksi kimia dalam tubuh dan menentukan kegiatan metabolik, misalnya dalam hal aktivitas fisiologis larva. Beberapa penelitian terdahulu menunjukkan bahwa setiap jenis ikan memiliki kisaran suhu optimum yang berbeda untuk proses perkembangan dan pertumbuhan larva (Okunsebor $e t$ al., 2015). Oleh karena itu, perlu dilakukan penelitian mengenai pengaruh pemberian suhu yang berbeda terhadap perkembangan dan pertumbuhan pada fase larva.

\section{Metode}

Penelitian ini dilakukan pada bulan Januari 2019. Rancangan yang digunakan dalam penelitian adalah

\footnotetext{
${ }^{1}$ E-mail: virgia34@gmail.com

${ }^{2}$ Jurusan Perikanan dan Kelautan, Fakultas Pertanian, Universitas Lampung

Jl. Prof. S. Brodjonegoro No.1 Gedong Meneng Bandar Lampung, 35145
} 
Rancangan Acak Lengkap (RAL) dengan tiga perlakuan $\left(26-28^{\circ} \mathrm{C}, 28\right.$ $30^{\circ} \mathrm{C}, 30-32^{\circ} \mathrm{C}$ ) dan tiga kali ulangan. Ikan uji yang digunakan adalah larva ikan kerapu macan yang baru menetas. Disiapkan 12 wadah aquarium pemeliharaan larva ikan kerapu macan. Jumlah larva ikan yang digunakan sebanyak 300 butir telur/wadah pemeliharaan. Parameter pengamatan meliputi:

\section{Volume Kuning Telur}

Volume kuning telur dihitung menggunakan persamaan Hemming dan Buddlington (1988) dalam Pramono et al. (2006), yaitu:

$$
\mathrm{V}=0,1667 \pi \mathrm{LH}^{2}
$$

Keterangan:

$\mathrm{V}$ : Volume kuning telur $\left(\mu \mathrm{m}^{3}\right)$

$\mathrm{L}$ : diameter kuning telur memanjang $(\mu \mathrm{m})$

$\mathrm{H}$ : diameter kuning telur memendek $(\mu \mathrm{m})$

\section{Pertumbuhan Panjang}

Pengukuran pertumbuhan panjang larva dilakukan dengan menggunakan persamaan menurut Zonneveld, Huisman dan Boon (1991) dalam Effendi (2004):

$$
\Delta \mathrm{L}=\mathrm{Lt}-\mathrm{Lo}
$$

Keterangan:

$\Delta \mathrm{L}$ : Pertumbuhan panjang mutlak

Lt : Panjang rata-rata ikan akhir pengamatan $(\mathrm{mm})$

Lo : Panjang rata-rata ikan awal pengamatan $(\mathrm{mm})$

\section{Perkembangan Morfogenesis Larva} Pengamatan morfogenesis dianalisis secara deskriptif waktu terbentuknya bagian tubuh dalam satuan waktu (jam).

\section{Pengukuran Kualitas Air}

Parameter kualitas air media pemeliharaan yang diukur selama penelitian meliputi suhu, $\mathrm{pH}$, salinitas, dan oksigen terlarut.

\section{Hasil dan Pembahasan}

\section{Perkembangan Morfogenesis}

Bintik mata pada tubuh bagian kepala larva kerapu macan mulai terbentuk pada jam ke-24 (Gambar 1.B). Hal ini menandakan bahwa larva mulai menggunakan kuning telur sebagai energi utama untuk perkembangan secara efisien.

Pada jam ke-30 mata larva sudah mulai terlihat menghitam dan membesar (Gambar 1.C). Pada jam ke-54 volume kuning telur sudah mulai menipis sehingga larva mulai mencari pakan alami untuk bertahan hidup.

Pada jam ke-60 terjadi pigmentasi pada bagian dorsal tubuh larva. Pada fase ini juga, mulut larva sudah mulai terbuka dan volume kuning telur terserap habis sehingga larva sudah mampu memangsa pakan alami yang tersedia secara optimum.

Pada jam ke-156 sudah mulai terbentuk bakal sirip perut dan punggung pada tubuh larva (Gambar 1.F). Pada fase ini larva sudah mulai perkembangan morfogenesis menuju bentuk tubuh yang sempurna.

Adapun hasil penelitian Purba et al. (1991) menunjukkan bahwa perkembangan morfogenesis larva kerapu macan pada suhu yang tinggi lebih cepat dibandingkan suhu yang rendah 

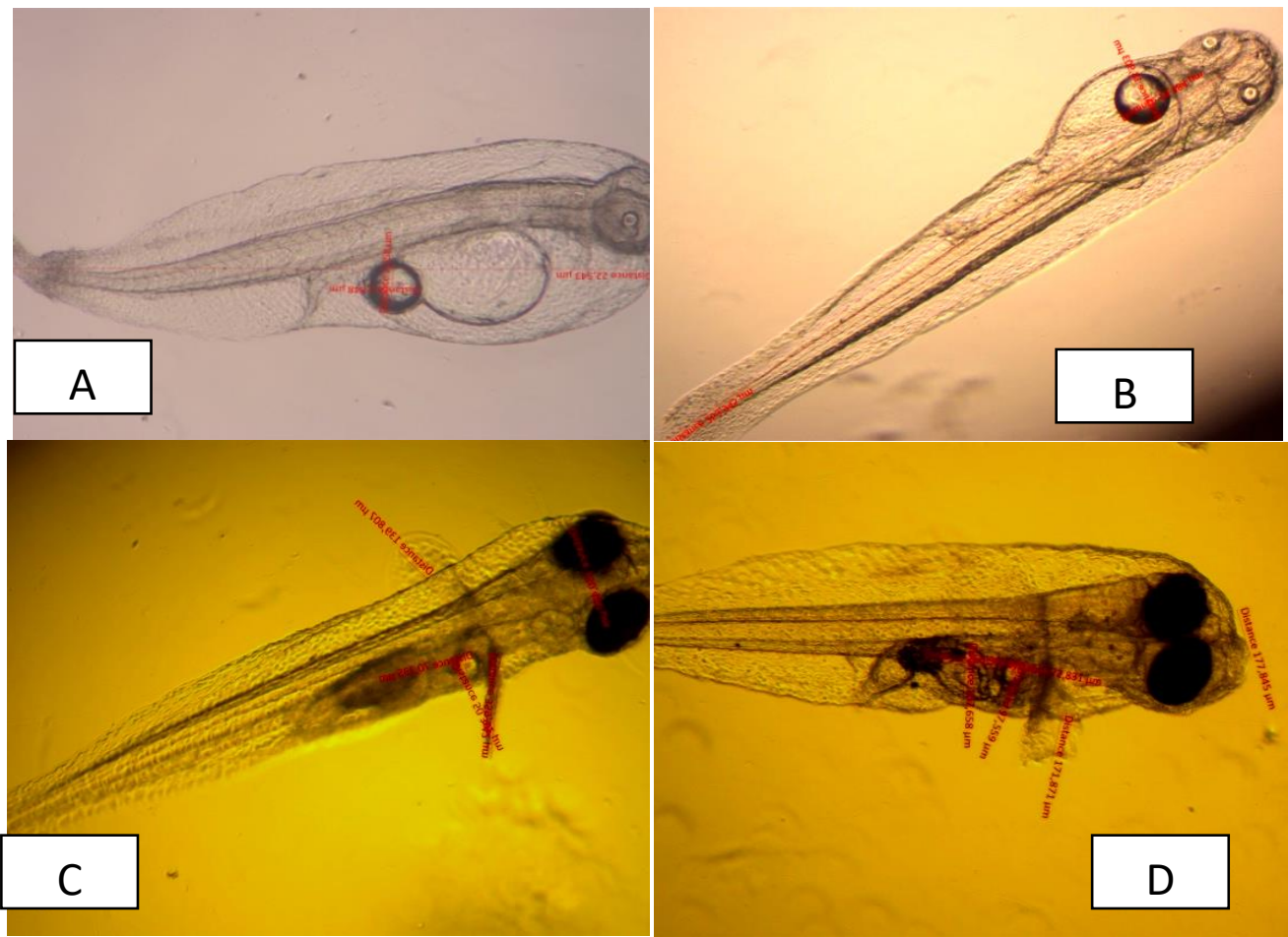

C

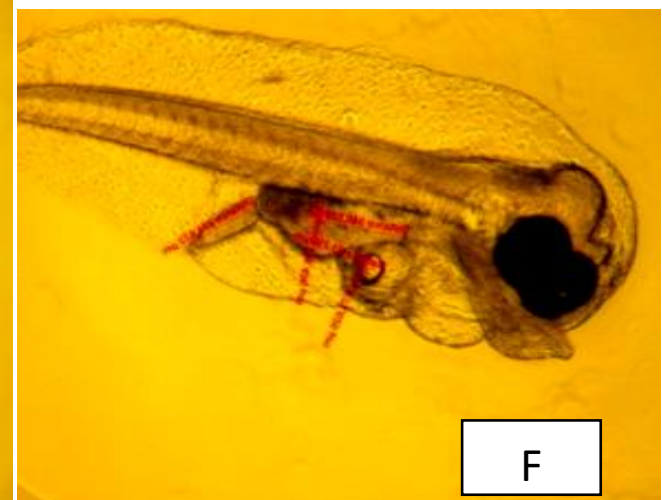

$\mathrm{E}$

Keterangan: (A) larva umur 0-1 jam, (B) larva umur 24-30 jam, (C) larva umur 30-36 jam, (D) larva umur 4254 jam, (E) larva umur 60-72, (F) larva umur 156-168.

Gambar 1. Perkembangan morfologi larva ikan kerapu macan

Penyusutan Volume Kuning Telur

Hasil pengamatan volume kuning telur disajikan pada Gambar 2. 


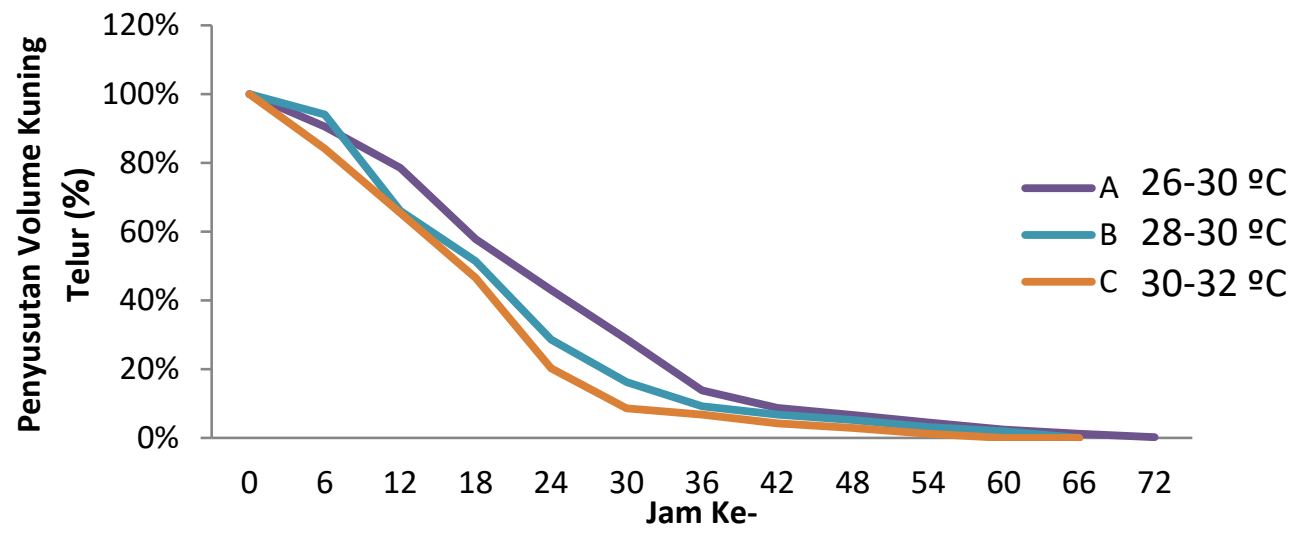

Gambar 2. Penyusutan volume kuning telur larva kerapu macan

Penyerapan volume kuning telur pada jam ke-24 cenderung lebih cepat sebesar $85 \%$ (Gambar 2) dan secara maksimum digunakan untuk melakukan perkembangan. Pada jam ke-36 hingga 72 penyerapan kuning telur cenderung terlihat lebih lama dan volume kuning telur sudah terlihat menipis. Pada jam ke-60 volume kuning telur pada larva hanya 2\% dari volume awal. Menurut Swanson (1996) penyerapan kuning telur meningkat dengan meningkatnya umur larva, bahkan pada umur satu hari volume kuning telur larva ikan bandeng, Chanos chanos, hanya tinggal $12-25 \%$. Purba
(1990) menyatakan bahwa pada suhu $27-33{ }^{\circ} \mathrm{C}$ proses penyerapan kuning telur pada larva kerapu macan lebih cepat sedangkan menurut Branko (1998) suhu $23{ }^{\circ} \mathrm{C}$ merupakan suhu optimum untuk laju penyerapan kuning telur pada larva ikan kerapu bintik merah.

\section{Durasi Penyerapan Kuning Telur}

Perlakuan suhu media yang berbeda mempengaruhi waktu penyerapan kuning telur yang berbeda juga. Perbedaan waktu penyerapan kuning telur disajikan pada Tabel 1.

Tabel 1. Durasi penyerapan kuning telur larva kerapu macan sampai habis

\begin{tabular}{cccc}
\hline \multirow{2}{*}{ Ulangan } & \multicolumn{3}{c}{ Waktu Penyerapan (jam) } \\
\cline { 2 - 4 } & $\mathbf{A}$ & $\mathbf{B}$ & $\mathbf{C}$ \\
\hline 1 & 72 & 66 & 60 \\
2 & 72 & 60 & 60 \\
3 & 72 & 66 & 54 \\
\hline Rata-rata & $72^{\mathrm{a}}$ & $64^{\mathrm{b}}$ & $58^{\mathrm{c}}$ \\
\hline
\end{tabular}

Keterangan: Huruf yang berbeda pada baris rata-rata menunjukkan nilai yang berbeda nyata pada selang kepercayaan $95 \%$

Hasil uji statistik dengan selang kepercayaan $95 \% \quad(\mathrm{p}>0,05)$ menunjukan bahwa perlakuan suhu yang berbeda berpengaruh terhadap waktu penyerapan yang berbeda. Hubungan suhu dengan waktu penyerapan kuning telur yaitu suhu mempengaruhi fisiologis larva dalam 
beraktivitas seperti respirasi, perkembangan, dan pertumbuhan. . Hal ini disebabkan pada saat larva melakukan aktivitasnya masih menggunakan kuning telur sebagai sumber energi dalam proses metabolisme. Apabila suhu tinggi maka proses metabolisme larva juga meningkat (Kohno, 1986).
Pertumbuhan Panjang Larva Ikan Kerapu Macan

Pertumbuhan panjang larva ikan kerapu macan meningkat seiring dengan pertambahan umur larva. Pertumbuhan panjang larva dan dapat dilihat pada Tabel 2.

Tabel 2. Pertumbuhan panjang larva kerapu macan saat 7 hari pemeliharaan (mm)

\begin{tabular}{ccccc}
\hline \multirow{2}{*}{ Perlakuan } & \multicolumn{3}{c}{ Ulangan } & \multirow{2}{*}{ Rata-rata } \\
\cline { 2 - 4 } & $\mathbf{1}$ & $\mathbf{2}$ & $\mathbf{3}$ & \\
\hline $\mathrm{A}$ & 2,11 & 2,49 & 2,47 & $2,31 \pm 0,21^{\mathrm{a}}$ \\
$\mathrm{B}$ & 2,50 & 2,96 & 3,08 & $2,85 \pm 0,31^{\mathrm{a}}$ \\
C & 2,25 & 2,55 & 2,61 & $2,47 \pm 0,20^{\mathrm{a}}$ \\
\hline
\end{tabular}

Keterangan: Huruf yang berbeda pada kolom rata-rata menunjukkan nilai yang berbeda nyata pada selang kepercayaan $95 \%$

Berdasarkan uji anova diketahui bahwa perlakuan suhu media yang berbeda terhadap pertumbuhan panjang larva tidak berbeda nyata. Pertumbuhan panjang larva ikan kerapu macan pada perlakuan B cenderung lebih cepat dibandingkan dengan perlakuan A dan C.

Pertumbuhan panjang larva kerapu yang dipelihara pada media pemeliharaan dengan suhu $28-30{ }^{\circ} \mathrm{C}$ (perlakuan B) cenderung lebih cepat meskipun suhu media pada perlakuan C lebih tinggi, yaitu $30-32^{\circ} \mathrm{C}$. Hal ini sesuai dengan pendapat Andriyanto (2013) yang menyatakan bahwa pada suhu yang lebih tinggi $\left(30-33{ }^{\circ} \mathrm{C}\right)$ pertumbuhan panjang relatif larva kerapu sunu lebih lambat dibandingkan dengan suhu optimumnya $\left(28-30^{\circ} \mathrm{C}\right)$.

\section{Parameter Kualitas Air}

Faktor yang mempengaruhi perkembangan dan pertumbuhan larva, diantaranya adalah suhu air, derajat keasaman $(\mathrm{pH})$, oksigen terlarut (DO) dan salinitas (Tabel 3).

Tabel 3. Hasil pengukuran kualitas air selama penelitian

\begin{tabular}{lcccc}
\hline \multirow{2}{*}{ Parameter } & \multirow{2}{*}{ Kisaran optimum } & \multicolumn{3}{c}{ Perlakuan } \\
\cline { 3 - 5 } & & $\mathbf{A}$ & $\mathbf{B}$ & $\mathbf{C}$ \\
\hline Salinitas (ppt) & $27-34^{1}$ & $32-33$ & $32-34$ & 34 \\
pH & $6,5-9,0^{2}$ & $7,4-7,6$ & $7,4-7,7$ & $7,5-7,7$ \\
DO (ppm) & $>3,5^{3}$ & $4,6-5,91$ & $4,96-5,42$ & $5,11-5,71$ \\
Suhu $\left({ }^{\circ} \mathrm{C}\right)$ & $26-30,5^{4}$ & $26-28$ & $28-30$ & $30-32$ \\
\hline
\end{tabular}

Keterangan:

${ }^{1}$ Suwoyo (2006), ${ }^{2}$ Boyd (1982), ${ }^{3}$ Chua (1978), ${ }^{4}$ Supito (1998) 
Pengukuran kualitas air selama 7 hari pemeliharaan larva ikan kerapu macan, nilai kualitas air dalam penelitian ini masih dalam kondisi yang optimum karena selama pemeliharaan larva selain dilakukan penyiponan secara rutin. Nilai $\mathrm{pH}$ pada penelitian ini berkisar 7,4-7,7. Kisaran tersebut masih dalam batas toleransi untuk pemeliharaan larva. Nilai pH yang optimum mempengaruhi kandungan kimia yang ada di dalam perairan.

Konsumsi oksigen berperan dalam proses metabolisme. Salinitas pada pemeliharaan larva selama penelitian berkisar 32-34. Salinitas berpengaruh terhadap aktivitas fisiologis di dalam tubuh ikan. Pemeliharaan ikan dalam media yang bersalinitas optimum mampu meminimalkan energi osmoregulasi dan memaksimalkan pertumbuhan.

\section{Kesimpulan}

Suhu media pemeliharaan yang optimum untuk perkembangan morfogenesis dan pertumbuhan panjang larva ikan kerapu macan adalah $28-30^{\circ} \mathrm{C}$. Adapun suhu $30-$ $32^{\circ} \mathrm{C}$ menyebabkan waktu penyerapan kuning telur larva ikan tersebut yang paling cepat.

\section{Daftar Pustaka}

Andriyanto. 2013. Perkembangan embrio dan rasio penetasan telur ikan kerapu raja sunu (Plectropoma laevis) pada suhu media berbeda. Jurnal Ilmu dan Teknologi Kelautan Tropis. 5(1):192-203.
Blaxter, H.S. 1969. Development of eggs and larvae. Academic Press. 3(9):189.

Boyd, E.C. 1982. Water quality management for pond fish culture. Elsevier Scientific Publishing Company, Netherland. 318 hal.

Chua, T.E. dan Teng, SK. 1978. Effects of feeding frequencyon the growth of young estuary nassau grouper E. tauvina (Forsskal, 1775). Aquaculture. 14(1):31-47.

Chen, F.Y, Chow, M., Chao, T.M., dan Lim, R. 1977. Artificial spawning and larval rearing of the grouper (Epinephelus tauvina) In Singapore. J. Pri. Indigenous 5(1): 1-21.

Effendi, I. dan Sumawidjaja, K. 2002. Pemberian pakan bagi larva ikan betutu (Oxyeleotris marmorata) pada dua minggu di awal hidupnya. Jurnal Akuakultur Indonesia. 1(3): 101-107.

Evalawati, M., Meiyana, dan Aditya, T.W. 2001. Biologi kerapu dalam pembesaran kerapu macan (E. fuscoguttatus) dan kerapu tikus (Cromileptes altivelis) di keramba jaring apung. BBL Lampung, Ditjenkan Budidaya, DKP, Lampung. 3-7 hal.

Ellis, W. 1997.Temperature effects on feed utilization an d growth of postsettlement stage nassau 
grouper. American Fisheries Society. 126: 309-315.

Hart, P.R. dan Purser, G.J. 1995. Effects of salinity and temperature on eggs and yolk sac larvae of the green back flounder (Rhomboselea tapirina Gunther, 1982). Aquaculture. 136(3): 221-230.

Hemming, T.A. dan Buddington, R.K. 1988. Yolk absorption in embrionic and larvae fishes. Journal Fish Physiology. 11(1): 178-253.

Heemstra, P.C. dan Randall, J.E. 1993. Serranidae groupers and sea bass. In The Living Marine Resources of the Western Central Pacific. 1(4): 24422546.

Hidayat. 2011. Kajian kualitas air pada budidaya kerapu macan (Epinephelus fuscoguttatus) sistem tumpang sari di areal mangrove. Jurnal Perikanan Terubuk. 39(2): 25-40.

Kohno, Hara, S., dan Taki, Y. 1986. Early larval development of the seabass, Lates calcarifer 1, with emphasis on the transition of energy sources. Bulletin of the Japanese of Scientific Fisheries. 52(10): 1719-1725.

Melianawati, R., Imanto, P.T., Suastika, M., dan Prijono, A. 2002. Perkembangan embrio dan penetasan telur ikan kerapu lumpur (Epinephelus coiodes) dengan suhu inkubasi berbeda.
Jurnal Penelitian Perikanan Indonesia. 8(3): 7-13.

Sakthivel, M. 2016. Effect of temperature on yolk sac utilisation and growth of newly hatched larvae of cobia Rachycentron canadum (Linnaeus, 1766). Indian $J$. Fish. 63(3): 135-139.

Nurdjana, M.L. 2010. Proyeksi produksi perikanan budidaya menurut komoditas utama 2009 s/d 2014. Publishing Forum Inovasi dan Teknologi Akuakultur. Puriskan Budidaya.

Okunsebor, S.A., Ofojekwu, P.C., Kakwi, D.G., Audu, B.S. 2015. Effect of temperature on fertilization, hatching and survival rates of heterobranchus bidorsalis eggs and hatchlings. British Journal of Applied Science \& Technology. 7(4): 372-376.

Pramono, T.B. dan Marnani, S. 2009. Pola penyerapan kuning telur dan proses perkembangan organogenesis pada stadia awal larva ikan senggaringan (Mystus nigriceps). Jurnal Terubuk. 37(1): 1-17.

Purba, R. dan Mayunar. 1991. Pengaruh salinitas dan temperature (suhu) terhadap kelulushidupan larva ikan kerapu macan (Ephinephelus fuscoguttatus). Jurnal Terubuk. 17(49):10-18. 
Quantz, G. 1985.Use of endogenous energy sources by larval turbot (Scophthalmus maximus). Trans Am Fish Soc. 11(4): 558563.

Regina. 2010. Perencanaan waktu tetas telur ikan kerapu dengan penggunaan suhu inkubasi yang berbeda. Jurnal Ilmu dan Teknologi Kelautan Tropis. 2(2): 83-91.

Dharma, S. dan Tony. 2015. Perkembangan embrio dan penyerapan nutrisi endogen pada larva dari pemijahan secara alami induk hasil budidaya ikan bawal laut (Trachinotus blocii). Jurnal Ilmu dan Teknologi Kelautan Tropis. 7(1): 83-90.

Supito, Kuntiyo, dan Djunaedah, I.S.. 1998. Kajian pendahuluan pembesaran kerapu macan (Epinephelus fuscoguttatus) di tambak. Prodsiding Seminar Teknologi Perikanan Pantai. Puslitbangkan, Loka Penelitian Perikanan Pantai Gondol-Bali bekerjasama dengan Japan International Cooperation Agency, Bali, 6-7 Agustus 1998. Hal 149-154.

Sugama, K., Ismi, S., Setiawati, K.M., Rimmer, M., McBride, S., dan Williams, K., 2004. Effect of water temperature on growth, survival and feeding rate of humpback grouper (Cromileptes altivelis) larvae. Monograph Series. 1(10): 6166.
Swanson, C. 1996. Early development of milk fish effect of salinity embrionic and larval metabolism yolk absorption and growth. Journal of Fish Biology. 4(8): 405-421.

Usman. 1999. Pemijahan dan pemeliharaan larva ikan kerapu bebek (Cromileptes altivelis). Fisheries Journal Garing. 8(2): 65-69.

Watanabe, T. dan V. Kiron. 1994. Prospect in larval fish dietics. Aquaculture. 9(124): 223-225. 